\title{
Towards Inclusive, Participatory Peer Tutor Development in Higher Education
}

\author{
Sherran Clarence \\ Rhodes University, South Africa
}

(Submitted 24 May; accepted 28 June 2018)

\begin{abstract}
Peer tutoring has a long history in academic support spaces in universities, such as writing centres and supplemental instruction programmes. Small group peer tutoring has moved increasingly into 'mainstream' teaching and learning, and has become an academic necessity in these spaces. The nature of student-tutor engagements in these spaces is about sharing and co-constructing knowledge, and developing more independent student learners. Yet, tutor development and training tends to under-prepare peer tutors to create participatory, inclusive tutorial environments. This paper argues for tutor development itself to model participatory, inclusive, and development practices, such that tutors learn from being part of the training process how to improve their practice. Drawing on qualitative data from a three-year project at a traditional, historically black South African university, this paper shows how such an approach yields benefits for tutors that include building knowledge about tutoring that overtly includes tutors' existing knowledge and experiences. Ultimately, a more inclusive approach to tutor development has a strong likelihood of changing tutoring praxis, making tutorials more participatory, inclusive, and shared spaces for learning.
\end{abstract}

Keywords: higher education, knowledge building, learning facilitation, participatory learning, peer tutoring

Peer tutoring has a long history in academic support spaces in universities, such as writing centres and supplemental instruction programmes. The nature of student-tutor engagements in these spaces is about sharing and developing ideas and co-constructing knowledge rather than teaching per se. Thus, much of the writing about peer tutoring from these perspectives is about collaboration, facilitation, and co-learning (Underhill, 2009; Layton, 2013). With the advent and growth of large classes, in large part due to open admissions or so-called 'massification' of higher education from the 1980s onwards in the US and the UK, and the early 1990s onwards in South Africa, small-group tutoring has become a firm feature of 'mainstream' teaching and learning. Tutorials are desirable in large class situations because they have the ability to provide a more 'intimate', 'student-centred' space in which students, with a peer tutor closer to them in age and experience, can work on problems, ask questions,

Vol.6, No. 1 (2018): pp. 58-74

Corresponding author: sherranclarence@gmail.com

doi: $10.14426 /$ cristal.v6i1.141 
and grapple with difficult knowledge (Layton, 2013; Underhill \& MacDonald, 2010; Shabanza, 2017).

The goal for tutorials is this intimate, student-centred, facilitative learning space, as opposed to a tutor-centred, didactic opportunity for a re-hash of the week's lectures. Yet, tutor development and training under-prepares peer tutors to achieve this goal (see Underhill \& MacDonald, 2010; Bell \& Mladenovic, 2015). It is indeed vital that tutors are assisted with understanding the disciplinary knowledge that students are working with, and identifying where the possible knowledge gaps and misunderstandings are, so that they can help students to work on these effectively (Underhill \& MacDonald, 2010; Layton \& McKenna, 2015). However, to avoid having tutorials become mini-lectures, where students are cast in a passive role as recipients of additional or revised knowledge (Bruffee, 1984), tutors need explicit training in advance of beginning tutoring, as well as ongoing support, that shows, rather than tells, them how to create the participatory, peer-focused tutoring environments that will enable student-led, independent learning (see also O’Neill, Harrington \& Bakhshi, 2009).

The most common forms of tutor 'training', in the context under study and in others in South Africa and globally (see Bell \& Mladenovic, 2015; Clarence, 2013; Underhill \& MacDonald, 2010) tend to be rather generic in nature, and focus on telling peer tutors useful ideas for group activities and dealing with difficult students, and why peer-led learning is important. It is widely acknowledged that lecturers need to be involved in tutor development and training, on an initial and ongoing basis, to form partnerships with the tutors they work with (Layton \& McKenna, 2015), and to ensure that tutors are further engaged in a disciplinary community of practice and learning (Underhill, Clarence-Fincham \& Petersen, 2014). However, Underhill et al. (2014), along with other researchers, have noted that many lecturers are overwhelmed by their teaching, administrative and research workloads, and struggle to add thoughtful, ongoing, and expert tutor development to their long list of tasks (Underhill \& MacDonald, 2010; Layton \& McKenna, 2015). Thus, partnerships between lecturers and academic development practitioners specialising in tutoring development can be a vital part of teaching and learning in higher education. These partnerships can address both the need for more engaged, participatory tutor development, and the need for lecturers working with tutors to be mentored and supported as they undertake this important task. This paper focuses on the first part - participatory tutor training - and points to how academic development can build on this to move towards greater engagement with lecturers, as they acknowledge the value of these forms of tutor development within their own disciplinary contexts.

Essentially, this paper argues that tutor training and development should ideally mimic the act of tutoring itself. In other words, the way in which we engage tutors needs to be collaborative, inclusive, and participatory in nature, incorporating tutors' own knowledge and experience as key sources of learning. While tutors undoubtedly draw on their own knowledge and experiences in the act of tutoring itself, it is less clear that the training and development opportunities offered to them use this knowledge and experience as the core basis for engaging peer tutors about their important role in relation to students. This paper looks at one instance of a tutor development programme that overtly centred peer tutors in the training, and used their own knowledge and experience as the starting point for learning about facilitation of learning, and creating shared, participatory student learning spaces. It 
argues that, rather than only imposing scholarly or common sense knowledge about learning and teaching onto tutors, effectively telling them what a good tutor is and does, tutors themselves need to generate this knowledge. Guided by a facilitator who can consolidate and add to this experiential knowledge, tutors can then be shown how a shared learning environment is created and nurtured.

\section{Massification, Tutoring, and the Need for Closer Student Engagement}

With the increasing growth of large classes, largely due to 'open admissions' or 'massification' of higher education (Hornsby \& Osman, 2014; Luckett \& Sutherland, 2000), small-group tutorials have become a common, and vital feature of the 'mainstream' curriculum, in South Africa especially (Underhill et al., 2014). They have been relatively common in academic support spaces, such as writing centres and extended and supplemental instruction programmes, for some time (Bell, 2001; Blaj-Ward, 2014; O'Neill et al., 2009; Clark, 1998; Underhill, 2009). However, they have become such a common feature of teaching and learning outside of academic support spaces because of their ability to provide 'intimate', student-centred, discussion-based learning spaces, where students can slow down, talk to one another, and with the help of a peer tutor, grapple with difficult knowledge, and knowledge gaps (Layton 2013). Yet, to provide these kinds of learning opportunities for students, tutors themselves need to be confident facilitators, able to step back and let students guide the discussions, and be able to fully value students' contributions to knowledge-making while also being able to correct misunderstandings and answer questions. This is no mean feat, especially if one considers that peer tutors are themselves students - usually postgraduate but in some cases also senior undergraduate students (Underhill \& McDonald, 2010).

In South Africa and other contexts, such as the United States and Canada, student tutors play significant roles in facilitating student learning in higher education. They are asked to run small-group (sometimes also larger-group) tutorials, assist in giving feedback on student writing, and provide ongoing academic support to students, as partners to lecturers. Yet, postgraduate student peer tutors (hereafter peer tutors) experience great variation in the kinds of professional or educational support, training, and development offered to them. In South Africa, there have been university-specific, or department-specific improvements in tutor development (Layton, 2013; Spark et al., 2017; Underhill \& Macdonald, 2010). But, on the whole across the higher education sector, peer tutors are more often than not underprepared for playing, specifically, facilitative academic roles with undergraduate students (Bell \& Mladenovic, 2015; Underhill \& McDonald, 2010). Studies have noted that disciplinary lecturers and tutor coordinators are often reluctant to offer training and support directly to their tutors, often for logistical or resource-related reasons, and thus elect to outsource this to academic development staff, or at least partner with academic developers to offer tutor development and support (Layton \& McKenna, 2015; Underhill et al., 2014). This may not be ideal, as structured support within their departments and disciplines offered throughout the academic year would be preferable (Bell \& Mladenovic, 2015; Clarence, 2016; Underhill et al., 2014). Academic development staff, therefore, have an opportunity here to make significant impact in creating different approaches to peer tutor development. 
Peer tutors tend to be selected on the basis of any or all of the following factors: prior experience of tutoring, subject knowledge, and willingness to be part of the tutoring programme (Underhill \& MacDonald, 2010; Spark et al., 2017). Thus, there may be an assumption on the part of tutor coordinators and lecturers that peer tutors have the requisite knowledge and skills needed to work with students. Consequently, 'training' offered may focus more on specific assessment tasks and marking memos, difficult sections of work that will be included in the tutorial curriculum, or other aspects of subject knowledge. What tends to be under-represented in tutor development and training, both initially and throughout the academic year, is input on how to facilitate learning, how to create inclusive and studentcentred learning spaces, and how to help students become more confident, capable learners. This is where academic development staff can partner with tutors, and academic departments, to tailor more general tutor development and support, and in the process influence departments' views on the role their tutors play in teaching and learning. It is important to note that this paper is not commenting on how lecturers develop tutorials themselves, as part of the curriculum, or the extent to which lecturers who work with tutors are, or are not, themselves capable and confident teachers. This is beyond the scope of this paper, which is interested in discussing how to create and sustain participatory, active and inclusive approaches to peer tutor development.

To be successful, and relevant to the individuals or groups concerned, developmental engagements need to acknowledge and build on prior and current teaching experiences, opinions, and ideas (Breda, Clement \& Waeytens, 2003; Knight \& Trowler, 2000). Collaboration goes hand-in-hand with mutual respect, enabling an academic department, or a tutoring collective in this case, to build a shared basis of knowledge and 'practice wisdom' (Bamber, 2014), which can be further developed over time. Thus, tutor-focused workshops on facilitating learning, giving feedback on student writing, or mediating engagement with knowledge need to make visible, validate, and build on tutors' existing knowledge and experiences. In other words, training should not be 'done unto' tutors, or come in the form of mini-lectures; rather, the knowledge should come from the tutors' themselves, and consolidate and extend what already exists. As already noted, it is almost certainly the case that peer tutors draw on their own experiences and knowledge when they are in a tutorial, with student learners. However, this knowledge and experience may lead to range of tutoring practices, not all of them desirable. For example, if a tutor has only had experiences of being a passive recipient of knowledge, they may undervalue group work, and opt for talking to students, rather than getting students to talk to one another. This knowledge may be tacitly drawn on in practice. But, effective and thoughtful tutor training can draw out this knowledge, make it explicit and open for discussion, and use it as a basis for reflection and ongoing learning.

Research indicates that experiential, meaningful learning occurs when learners $d o$, rather than when they are told what to do. In other words, workshop participants need to actually participate in activities that draw on their knowledge and experiences, offer opportunities for practicing new skills, and model or mimic the kinds of facilitation or teaching expected of them (Beck et al., 1978; Bell \& Mladenovic, 2015; O'Neill et al., 2009). Further, making reflection part of the training process encourages tutors to become more conscious of their beliefs, understanding, and values as regards their tutoring role (O'Neill et 
al., 2009; Bell, 2001; Bell \& Mladenovic, 2015). Implied in this research is that peer tutors can begin to learn how to tutor more effectively by participating in workshop-style engagements that mimic a desirable tutoring environment. The benefits are that tutors get to know the peers they are tutoring alongside, they receive valuable materials and information that can inform their in-tutorial activities, and the facilitator can grasp a valuable opportunity to model successful or useful tutorial activities or practices. The chief limitation of these workshops is that they are, by necessity, more general than discipline-specific. Ideally, lecturers need to attend with their tutors, and use the tools and materials in their own ongoing disciplinary meetings to supplement and enhance these. These proposed participatory, tutorcentred workshops are the focus of this paper.

\section{Research Context}

Before moving into the details of the workshops, an outline of the context for this research would be useful. The university in which these workshops were conducted as part of a threeyear long study into tutorial, and tutor, development is a mid-size, historically black, traditional institution. When the research project was launched in 2012, tutor development and training on campus was patchy, with some academic departments engaging their tutors in initial and ongoing training, while the majority of lecturers met with their tutors sporadically. The focus of the meetings, whether regular or sporadic, tended to focus on marking memos for tutorial assignments, going over lecture materials to point to possible knowledge gaps and challenges that tutorials could address, and problems raised by tutors about previous tutorials (Clarence, 2013). An online survey sent to all departments within the university in 2012, which did not have a $100 \%$ response rate but was representative as it included all seven faculties, revealed 976 peer tutors working with students. The numbers were fairly similar in 2013 as well (Clarence, 2013). The peer tutors in this research context, as in many others, work mainly with first and second year undergraduate students, and most are postgraduate students, although a number are senior undergraduate students (third or fourth year students). Thus, there was a significant need for a more thoughtful, multi-level approach to tutor development and training.

While engaging with lecturers about their own role in developing their tutors was part of the project, a significant part of the initial work was creating initial and ongoing workshops, to which tutors and lecturers were invited. The survey and roundtable research conducted by the author in 2012 and 2013 indicated rather passive approaches to training tutors went to meetings, and apart from discussion with the lecturer, were given information, given a memo and taken through it, and given some ideas of how to engage students. There was too little indication that tutors' own knowledge, experiences, and insights were actively and overtly used as a basis for further learning and knowledge-building about tutoring, learning and teaching. Thus, a first step was to develop workshop-style training, at the start of the academic year, and at the mid-point after June exams, for tutors across faculties to equip them to create more active, inclusive, participatory tutorial spaces. These workshops were designed in consultation with lecturers and faculty teaching and learning specialists, although not all lecturers were able or willing to be part of this process. They were piloted in 2013, and refined and further run in 2014, facilitated by a teaching and learning specialist tasked with university-wide tutor development (also the researcher and author of this paper). 


\section{The Tutor/Participant-led Activities}

The inspiration for the activities used in the workshops (see Figures 1 and 2) came from an approach to participant-led or inclusive research termed 'participatory action research'. The core principles of this approach, relevant to the research discussed in this paper, are that it is focused on creating change, and this change is decided on and instigated by the participants. Further, all knowledge relevant to creating change in the context is generated collaboratively and reflexively by the participants and facilitator, working in collaboration (https://participaction.wordpress.com/whatpar/defining-par/). Key is that knowledge is not imposed on the participants from outside of the community, but comes from the community itself, and can be enhanced and added to but not 'talked over' or devalued. This approach to research strongly values participants' subjective experiences of the issue being researched in this case development opportunities offered to peer tutors in higher education - and sees these experiences as a valid form of powerful knowledge.

\section{SESSION 1 (2.5 hours with break) \\ [Input on matrix ranking and $\mathrm{T} / \mathrm{P} / \mathrm{S}$ ] \\ What makes a tutor successful?}

THINK PAIR SHARE - On their own to jot down notes and then share in pairs and then with 3 pairs together.

In the group of 6 , groups do a matrix ranking where they pool all their ideas, identify 5 main themes and then rank those by voting with counters. Groups to put these matrices onto flip chart paper and share with whole group. Facilitator to collate and summarise responses as consolidation.

\section{What makes a tutorial successful?}

Video Clips (4 short clips)

Small group discussion - THINK TANK. Small groups to brainstorm and generate ideas for 10 minutes and then do a matrix ranking. This is shared with whole group and facilitator consolidates.

Wrap up: Summary of what successful tutors and tutoring are/could be, and short input to add further thoughts and direction.

SESSION 2 (2 hours with short break)

Managing and facilitating tutorials

Role-plays - small groups given scenarios to act out different kinds of tutorial conversations ranging from well-run to challenging. Whole group and facilitator to comment and give input.

Formal input: What does it mean to facilitate learning and what tools can we use to draw students into productive learning environments?

Tutors to try out different tools 
Jigsaw puzzle/Buzz Groups/Send a problem/Freewrite/Think Pair Share

Set these up and handouts for groups. Group discussion on how these tools worked and possible advantages and disadvantages.

Wrap up: facilitation of learning and management of tutorials linked to what makes tutorials and tutors successful, and faculty/department expectations of tutors' roles and responsibilities.

Feedback and close.

\section{Figure 1: Programme for initial tutor training workshop - 2013}

Session 1: $9.30-12$ noon (comfort break of 15 minutes roughly halfway through)

1. Welcome, introductions, short icebreaker (motivation for tutoring)

2. First activity: What does it mean to 'engage' in learning? What is active or interactive learning? Small group work - plenary sharing

3. Input: university's student profile, $T \& L$ view on what it means to engage students in learning and what tutorials should ideally be

4. Second activity: good tutor/bad tutor - using tutors' own experiences as students to draw out some guiding principles for successful tutors and tutorials in their disciplines

Session 2: $1-3.30 \mathrm{pm}$ (comfort break of 15 minutes roughly halfway through)

1. First activity: what does it mean to facilitate learning and what are some of the ways in which we can do this as tutors?

2. Input: Facilitation and questioning tools for managing or guiding tutorials - how do we make things go right and what happens when things go wrong?

3. Second activity: Role-plays - small groups given scenarios to act out different kinds of tutorial conversations ranging from well-run to challenging. Tutors to try out different tools in small groups on a certain topic and to give feedback on how these worked and what they like or don't like about these tools and how they could use them. Disciplines who send tutors need to provide tutorial tasks or memos to use as examples. Whole group and facilitator to comment and give input and feedback on the role plays.

Feedback and close.

Figure 2: Programme for initial tutor training workshop - 2014

The activities used in these workshops are fairly simple, as the workshops are introductory, and often one day is the maximum amount of time a department can set aside for such training. The time is also limited to a day or a morning based on tutors' own feedback that longer training engagement is difficult to make time for, as they are engaged in their own studies, and it can be difficult to focus for longer periods of time. Thus, to work with, rather than against, the context, the workshops were designed to maximise the time made available. However, this simplicity enables tutors, with very little input, to engage effectively with their own knowledge and experience, sharing and reflecting on this with their 
peers and the facilitator. The workshops use the same tools for discussion and group work that tutors are encouraged to use in their tutorials. This further calls for simple, accessible activities that can be successfully managed within the length of an average 45-minute tutorial or workshop sub-session.

The first activity used in the initial workshops in 2013, 'matrix ranking', is a participatory action research tool. This activity can be run in more and less complex ways (see, for example, Mahesh et al., 2017), but given the nature of, and time for, these tutoring workshops, a simplified and adapted version was adopted. The tutors divided into groups of around 5 people per group, depending on whole group numbers, and each small group received flipchart paper and a koki pen. They began by brainstorming a list of ideas around the given topic; in the case of the tutoring workshops, these were basic guidelines for being a successful tutor, and facilitating a successful tutorial. This list was then refined and a set number of options was then written down, as brainstorming often leads to points being repeated, or similar points being phrased differently, meaning these can be merged into one point. Eight to ten points per matrix is manageable. Tutors then voted on the order of importance, based on their views and experience. Each participant was given the same number of beans, or paperclips, to vote with, and could cast as many votes as they wanted for their preferred choices. In practice, this might look like a written list of eight statements about the characteristics of a successful tutor, and eight statements about the characteristics of a successful tutorial. If a tutor has 20 voting beans they could put 10 on their first choice, 4 on their second, and 2 each on a further 3 points that have similar relevance to one another. Disagreements could then be debated, arguments could be made for and against certain rankings, and tutors could change their votes if they wished to. The final ranking, voted on by the tutors, was then captured, and became the 'manifesto' for tutoring for that group. This 'manifesto' was captured by the facilitator, who guided and advised groups throughout. Each group of tutors, as well as the tutor coordinator and lecturers, was then e-mailed their manifesto, and this then became a useful ongoing reference throughout the year.

This activity was repeated, with a twist, in 2014 (Figure 2), as 'Good Tutor/Bad Tutor'. This title was presented as overtly fun, and tongue-in-cheek, acknowledging that a better title would be More Successful Tutor/Less Successful Tutor. But this is not very catchy, as participants noted, hence the more cheeky title. Part of the goal of these workshops is also to make them fun, so that tutors are excited for the task ahead, and go into tutoring with that spirit of enthusiasm, and with materials and ideas to try out with their students. In the 2014 round, matrices were abandoned as the process of debating and arguing, while fruitful, proved to be too time-consuming for the short 45 minutes allocated to the activity within the structure of the whole workshop. The 2014 activity, rather, focused on tutors sharing, again in small groups, their own experiences of being tutored in the past. They were asked to consider who their favourite tutor was, and why, and who their least favourite tutor was, and why. The small groups then collated the responses, as some were repeated by more than one tutor, and shared the group's 'list' in the plenary session. This time around the facilitator captured the points on a whiteboard, thus enabling all the groups to share their points, often repeating and consolidating what others had said, but making the capturing quicker, as repetitions did not need to be written down. There were still opportunities for reflection and debate, but these took less of the session time in the revised activity format. 
These whiteboards were photographed, and later transcribed for the groups so that the 'manifesto' element remained (see Figure 3).

In both instances of this initial, beginning of the year workshop activity, the knowledge about what makes tutors, and the tutorial itself, successful (or unsuccessful) came from the tutors themselves. The facilitator ensured the discussion stayed on track, and that everyone worked towards the common goal for the session, and kept time. Further, the facilitator consolidated the group discussions, reiterating important points, and adding, where relevant, broader insights from research and the experiences of tutors in other faculties. This showed tutors who felt perhaps that their experiences were unique, or due to their own failings, that they were not alone, either within the university or the wider peer tutoring community. The peer tutors hopefully felt inspired by the 'manifesto' and were able to keep referring to it throughout the year, given that they created it, as opposed to having external 'principles of good tutoring' given to them.

\section{A successful tutor is...}

- Motivated and enthusiastic; someone with good 'people skills'

- Approachable and accessible

- Knowledgeable about the subject matter

- Resourceful and creative when necessary

- Empathetic and a good listener

- Punctual and good at managing time during tutorials

- Well-prepared, but also able to be flexible when addressing students' questions and needs

- A facilitator of others' learning rather than an expert

Successful tutorials...

- Are spaces of mutual respect

- Create a web of learning and link clearly to the rest of the course

- Identify and resolves problems and questions before moving on

- Are interactive and less formal than lectures

- Are participatory - where students get to talk a lot more than the tutor and engage on their own learning more actively

- Give students feedback on where they are going wrong and also praise students where they are doing well

- Have clear outcomes, and are guided by instructions from lecturers so that they fit into the rest of the course

- Try to reach all students and make the lecture content/course content clearer and more applicable and understandable

Figure 3: Example of matrix ranking exercise 'manifesto', 2013 


\section{Methodology and Data}

The data drawn on in this paper is qualitative. The larger study this paper references, run between 2012 and 2014, was qualitative in nature, aimed at researching, piloting and evaluating novel, participatory methods of training and developing peer tutors working across six faculties at a mid-size, traditional South African university. The workshops were designed to offer peer tutors, both new and experienced, a participatory introduction to core principles of learning facilitation and peer tutoring at university. Key to the workshop design was the overt inclusion, and reflection on, tutors' own knowledge and experience, either of prior tutoring, or of being a tutee. All the tutors received support materials on group work activities, and giving feedback on student writing, although only group work and facilitation of learning were the focus of the initial workshops due to time constraints. All departments that elected to come to the training received invitations to ongoing workshops throughout the year, several of which were successfully facilitated in June and September during the semester and term breaks. These are not, however, included in this data set or paper.

The basic programmes for 2013 and 2014 are included above in Figures 1 and 2. The workshop plans changed in 2014, with feedback from lecturers, tutor coordinators, and the peer tutors' themselves, in conjunction with the facilitator's own further reading and reflection. The basic elements of the input, however, were the same, focused on what makes tutors and tutorials successful, and how to move away from mini-lectures towards facilitated, participatory tutorials.

All of the departments who sent their tutors to the workshops did so voluntarily, and attendees included, in a few cases, tutor coordinators and lecturers. In 2013, 9 departments requested this workshop, from the faculties of Arts, Law, and Community and Health Sciences. In 2014, 6 departments requested this workshop, from the same three faculties. [The reduction in numbers was due largely to certain departments taking on the responsibility for training their own tutors 'in house'.] The peer tutors in this study were all postgraduate and senior undergraduate students, who were selected to tutor because of their prior experience, willingness, and subject knowledge (read as good academic performance). The same initial one-day workshop was run in each department at the start of the academic year (February), with minor adjustments, largely in verbal examples used in facilitation, based on the audience. To the extent that this was feasible, the facilitator included lecturers and tutor coordinators in the planning of the workshops, and tailored the examples used in plenary discussion to the subjects tutors were working within, drawing as much as possible from tutors' own inputs.

The two activities that have been selected to focus on here, partly for reasons of space constraints, and partly based on their frequent mentions in the tutors' feedback on the workshops, are those mentioned in the preceding section. The data that will be drawn on in the paper includes tutors' written responses to these two exercises, written feedback on their experience of the workshop, and the facilitator's written reports and notes, captured postworkshop.

The data were analysed using thematic content analysis, with theme development and refinement guided by the literature, the aims of the workshops, and the goal of creating participatory tutor training. The data were read iteratively, loosely coded first with descriptive categories such as 'participation enabled' and 'fun to take part'. Further 
refinement of the themes led to certain themes being merged into firmer categories, such as 'Tutors building on prior knowledge/learning useful knowledge', and 'Challenges didactic, hierarchical modes/models tutoring praxis'. The final themes that have emerged most relevantly are: creating space for active, peer-focused participation; modelling facilitation of learning; and building new tutoring knowledge. These are discussed in detail, with excerpts from the data, in the following section. Key words within the data excerpts that pertain to the focus of this paper have been highlighted in bold.

\section{Findings and Discussion}

\section{Creating space for active, peer-focused participation}

The first theme that emerged, largely from the facilitator's reflections in a report to the departments, and the participants' detailed narrative feedback written at the end of the workshop, is that of peer-to-peer, participatory learning. The facilitator noted, in her report, high levels of enthusiasm for the tasks, with participants engaged with one another in sharing experiences, debating their meaning, and enjoying the experience. This was particularly noticeable in the matrix ranking exercise in 2013, although all of the group activities in both years elicited high levels of engagement (Facilitator report 1,2).

The peer tutor participants noted the levels of interaction in their narrative feedback (essentially this means they do not fill in an evaluation form, but simply write in prose about high and low points, and elements they think could be improved upon).

The initial training was important because it prepared me for the year. One of the things which was most helpful was that the training was participatory. This made it possible to remember the training and it made the training exciting.

I thought that the workshop was really interactive and informative. I enjoyed it from beginning till the end and it had opened my mind to new things.

A key element of the 'exciting' and 'interactive' nature of the workshops was the engagement not just between the facilitator and participants, but also between the participants as peers. The tutors could see the value of engaging with their peers, in terms of creating a sense of teamwork, and also learning from one another. This was especially useful in interactions between new and experienced tutors.

It was very exposing to be in a group and bounce off ideas off each other - was a good experience.

Group work - team co-operation, shared info and knowledge, learning from other people.

Engaging with my colleagues particularly on tutoring and get to learn from how other tutors carry out classes especially in areas where there are weaknesses on my part, particularly when the workshops are noisy. 
The tutors highlighted the shared nature of knowledge, and the ways in which the group activities created a space for them to learn from one another. This is especially important in terms of modelling the empowering nature of such a learning environment: ideally the learning for tutors is that creating similar shared environments in their tutorials could result in similar experiences for their student tutees.

\section{Modelling facilitation of learning}

A further, and connected, issue that emerged in the data, as a direct result of the nature of the facilitation and activities used in the workshops, is the modelling of desired modes of facilitation and engagement. The workshops were purposefully designed (see Figures 1 and 2) to not only make the morning, or day, fun and interesting for participants; a significant point in the design was to create a tutorial-like atmosphere and 'model' successful modes of tutoring. An underlying aim was, through participation and experience, rather than words, to challenge hierarchical, didactic modes of engagement, where the tutor is expert cast against the student novices. The workshops needed to challenge tutors on this creatively; simply telling them not to teach does not help them move towards creating shared, participatory tutorials. Their feedback, and inputs during the workshops, bore this out:

It [this workshop] ... not only supplies you with the necessary tools in order to handle students and bring out the best in them, however, it allows you to practice and place yourself in the actual position/situation of how it would be when one tutors. It is very exciting, informative and gives one confidence in entering the tutor journey.

The workshop was interesting as it made me think about ways to improve my method of facilitating and teaching. It also showed me how I will be able to guide and aid my students to be more independent, and so allow them to grow as stronger students with greater confidence.

This tutorial seminar was very very insightful. I believe that I learned how to be open minded, yet cautious, how to be a facilitator yet eager to learn, now to be respectful, yet never doubt myself, how to lead with authority yet never be authoritative. I learned that it is an immense responsibility that has been placed on my shoulders, I will be shaping the minds of young people encouraging them to think critically about the word, their surroundings and themselves. I hope I do not make them into little 'me's.

This feedback is encouraging, because it shows that the tutors - without being told that this was an explicit aim of the style of the workshops - understood that they were being guided towards thinking of learning and tutoring in more facilitative, rather than didactic, ways. This points back to research that has emerged primarily from writing centres and academic support programmes, which underscores the value of learning collaboratively, through doing rather than being told (see O'Neill et al., 2009; Bruffee, 1984). It also underscores research into tutor development and training, which argues for involving tutors' own knowledge and 
experience in the development process, and building on as well as consolidating - and in some cases challenging - this (Layton, 2013; Underhill \& MacDonald, 2010).

\section{Building new tutoring knowledge}

This brings us to the final issue that emerged from the data, and that formed a key impetus for designing and facilitating the workshops in the way this was done. This is to build new tutoring knowledge not through imposing external theory or constructs onto tutors, but rather through starting with their own knowledges and experiences and building on these.

Specifically, the workshops sought to build on relevant, and accessible knowledge: that of having been tutored (as a student), and that of being a tutor or mentor to others. Even if a tutor is new to that role, they have all encountered lecturers and tutors as students, and all of them have an experience of being in either an empowering or disempowering learning situation (or both). They thus have knowledge that can be brought into a broader understanding of the role of a peer tutor, and the purpose of learning and teaching in higher education. Their own knowledge, gleaned from their experiences, can be consolidated, and built upon. It can also be challenged by a facilitator who connects tutors' stories and experiences together through plenary feedback, and then connects these with scholarly research and input, so that tutors have a multi-level understanding of the 'immense responsibility' they have.

It made me to reflect on my tutoring, and my students and my impact as a tutor in creating knowledge.

Learned some new techniques to use in the tuts. Facilitator was able to pull 'threads' of what we say together well.

I like how we are able to reflect on past experiences in our lives and then relate it to tutoring, help us realise that we are the instruments for student support.

By brainstorming the qualities tutors require I am able to reflect on my own qualities and then can improve or enhance it to make me a better tutor.

Further, there were comments about being able to share their thoughts and input openly, and without fear of criticism: one tutor commented that it was lovely 'To have spoken my mind and ... not [be] criticised on it'. Others also spoke about how everyone was 'included and our views were included and it made it so much more fun and we learnt more'. This is important when considering knowledge-building as a focus of tutoring. If students feel that the space cannot include their voices, their knowledge or their views, they will be less likely to really engage, and their learning and enjoyment of that learning may be compromised. Tutorials, as the tutors noted in their feedback, are about knowledge creation, not just knowledge acquisition. This is an active process, and tutorials must then rise to this challenge to enable students to be active, and to feel that the tutorial space is theirs, shared with the tutor. 


\section{Conclusion}

One of the most interesting observations, in light of the participatory, inclusive aims underpinning these tutor development workshops, was that several tutors commented that they were surprised (but pleased) to have been given an active role.

... it wasn't a lecture (which I expected) hearing the different viewpoints and giving input was great.

And,

We went to another training thing last week and it was just giving us notes and things. This was different - I didn't know what to expect - but we were all included

Regardless of whether tutors are working in a writing centre, an academic support programme, or a 'mainstream' module within a degree programme, the literature agrees that tutorials should be spaces that encourage and enable participation, and peer-to-peer learning. The tutor, in this scenario, is also a peer: there to guide, facilitate, question and also learn. But, this act of engaged, non-hierarchical facilitation, that creates a shared learning space, is difficult to do. The didactic approach to teaching and learning remains dominant in higher education (Northedge 2003; Case 2007), and it has to be constantly challenged. This is difficult enough for lecturers, hired to teach and often offered opportunities for continuous professional development to help them do this, such as postgraduate diplomas in higher education and short courses on curriculum design, pedagogy and assessment (see www.chec.ac.za for examples). How much more difficult, then, for peer tutors who are predominantly postgraduate and senior undergraduate tutors, many of whom have come up in a predominantly didactic system and have relatively few examples to draw on that show them how to be more participatory, and facilitative in their approach?

As noted earlier in the paper, there is a need to include lecturers in tutor development far more extensively, and other research has looked in-depth at how to work with lecturers to develop more inclusive tutorials within the curriculum (Clarence, Wolff, Winberg, Farmer \& Esambe, 2016), and how to work with junior lecturers in particular to enhance their own teaching practice so as to better support their tutors (Underhill et al., 2014). It is prudent, though, to learn to work with, rather than against, one's contextual limitations, so as to slowly, but firmly, instigate and nurture change. To this end, rather than only focusing on lecturers, or only working within disciplinary contexts, as some research suggests is most necessary, this project aimed to work with the group that, in this context, appeared to need the support most urgently: the peer tutors. Through these workshops, lecturers were drawn in: as attendees, through feedback given to all departments, and through the ongoing roundtable discussions and surveys that formed part of the project.

The research in the field, and that which was incorporated within the larger project implicated in this paper, points to a firm need to challenge an assumption that peer tutors already possess the skills they need to tutor, or that minimal input through 'notes and things' will be sufficient. As argued elsewhere (Clarence, 2016; Underhill \& MacDonald, 2010; 
Underhill et al., 2014), what is needed in ongoing, thoughtful support, and as argued here, that support needs to focus on modelling successful tutorial practices, starting with and building on tutors' own knowledge and experience. Participatory tutor development recognises tutors as a primary source of knowledge, and rich experience, and incorporates this to show tutors that they already possess some of the ability and skill they need. It takes this a step or two further, though, to model useful activities that can be employed in tutorials, to build on and challenge some assumptions and knowledge of tutoring and learning, and to encourage tutors to approach their work with courage and enthusiasm. The workshops ultimately encourage, in the spirit of participatory action research, change: change that is instigated by members of the community or context in question, and that will benefit all involved, in this case, students, tutors, lecturers, and the wider university community they are all part of. The words of one of the participants sum up the point of this approach to tutor development well:

I think that this training helps to break the mould of top-down structure which still seems to remain firmly in place. Lecturers need to attend a session too. We need to move beyond the hierarchical structure of learning because it remains an on-going process - learning. It is life-long.

Sherran Clarence is an honorary research associate in the Centre for Postgraduate Studies at Rhodes University. Her current work centres around postgraduate and early career research and writing, and her research straddles academic staff development and academic writing pedagogies. She is currently working on a monograph focused on using Legitimation Code Theory to improve undergraduate teaching and learning.

\section{References}

Bamber, V. 2014. Keynote address. Higher Education Close-Up (HECU) 7 Conference, Lancaster University, 21-23 July 2014.

Beck, P., Hawkins, T., Silver, M., Bruffee, K.A., Fishman, J. \& Matsunobu, J.T., 1978. Training and using peer tutors. College English, 40(4): 432-449.

Bell, J. 2001. Tutor training and reflection on practice. The Writing Center Journal, 21(2): 79-98.

Bell, A. \& Mladenovic, R. 2015. Situated learning, reflective practice and conceptual expansion: effective peer observation for tutor development. Teaching in Higher Education, 20(1), 24-36.

Blaj-Ward, L. 2014. Researching tutor participation in the EAP learning context. In Researching Contexts, Practices and Pedagogies in English for Academic Purposes. London: Palgrave Macmillan, 113-144.

Breda, J., Clement, M. \& Waeytens, K. 2003. An interactive training programme for beginning faculty: issues of implementation. International Journal for Academic Development, 8(1-2): 91-104.

Bruffee, K. 1984. Collaborative learning and the 'conversation of mankind'. College English, 46(7): 635-652. 
Case, J. M. 2007. Alienation and engagement: Exploring students' experiences of studying engineering. Teaching in Higher Education, 12(1), 119-133. http://dx.doi.org/10.1080/13562510601102354.

CHEC. 2018. Quality teaching in higher education. Short Courses in 2018. Cape Higher Education http://www.chec.ac.za/files/CHEC\%20QTHE\%20PROGRAMME\%202018\%20update. pdf (Accessed 20 May 2018)

Clarence, S. 2013. Reconceptualising tutor training at UWC. Paper presented at the UWC Annual Teaching and Learning Colloquium, Belville, July 2013. https://www.youtube.com/watch? $\mathrm{v}=\mathrm{m} \_5 \mathrm{p} 736 \mathrm{kwE} 8 \& \mathrm{t}=1304 \mathrm{~s}$ (Accessed 25 March 2018).

Clarence, S. 2016. Peer tutors as learning and teaching partners: a cumulative approach to building peer tutoring capacity in higher education. Critical Studies in Teaching and Learning, 4(1): 39-54, http://dx.doi.org/10.14426/cristal.v4i1.69.

Clarence, S., Wolff, K.E., Winberg, S., Farmer, J-L., \& Esambe, E.E. 2016. Transforming the use of tutorials in higher education through academic staff development. Paper presented at the International Consortium for Higher Education/HELTASA conference, Cape Town, November 2016.

Clark, S. 1998. Tutor development. Finding a language for teaching. In Angelil-Carter, S. ed. Access to Success: Academic Literacy in Higher Education. Cape Town: UCT Press, $120-134$.

Hornsby, D.J. \& Osman, R. 2014. Massification in higher education: large classes and student learning. Higher Education, 67(6): 711-719.

Knight, P.T. \& Trowler, P.R. 2000. Department-level cultures and the improvement of learning and teaching. Studies in Higher Education, 25(1): 69-83.

Layton, D. 2013. A Social Realist Account of the Tutorial System at the University of Johannesburg. Unpublished PhD diss., Rhodes University.

Layton, D. \& McKenna, S. 2015. Partnerships and parents-relationships in tutorial programmes. Higher Education Research \& Development, 1-13. DOI: 10.1080/07294360.2015.1087471.

Luckett, K. \& Sutherland, L. 2000. Assessment practices that improve teaching and learning. In Makoni, S. (Ed), Improving teaching and learning in higher education: a handbook for Southern Africa. Johannesburg: Witwatersrand University Press, 98-130.

Mahesh, V., Swathi Lekshmi, P.S., Ananda Pawar, D., Daliyamol, Kumar, A. \& Prakash, P. 2017. Matrix Ranking- An important PRA tool to assess farmers preferences and priorities. Agric. Sci. Digest., 37(2): 100-105.

Northedge, A. 2003. Enabling Participation in Academic Discourse. Teaching in Higher Education, 8(2): 169-180.

O’Neill, P., Harrington, K. \& Bakhshi, S. 2009. Training Peer Tutors in Writing: A Pragmatic, Research-based Approach. Zeitschrift Schreiben, 21 October, 1-10.

Shabanza, K.J. 2017. Enhancing reflection on writing. Using group writing consultations to develop meta-awareness of disciplinary writing. In Clarence, S. and Dison, L. (Eds), Writing Centres in Higher Education. Working in and across the disciplines. Stellenbosch: SUNPress, 161-174. 
Spark, L., de Klerk, D., Maleswena, T. \& Jones, A. 2017. Paving the Road to Success: A Framework for Implementing the Success Tutoring Approach. Journal of Student Affairs in Africa, 5(2): 75-88. DOI: 10.24085/jsaa.v5i2.2703.

Participatory Action Research and Organizational Change. n.d. Defining PAR. https://participaction.wordpress.com/whatpar/defining-par/ (Accessed 20 May 2018).

Underhill, J. 2009. The role of a peer tutor development programme in an academic literacies module. Unpublished Masters thesis, University of Johannesburg.

Underhill, J. \& McDonald, J. 2010. Collaborative tutor development: Enabling a transformative paradigm in a South African University. Mentoring \& Tutoring: Partnership in Learning, 18(2): 91-106.

Underhill, J., Clarence-Fincham, J., \& Petersen, N. 2014. Developing a mentorship programme for junior lecturers working with student tutors at a South African university: Emerging shifts in pedagogy and identity. Education as Change, 18(2): 357-371.

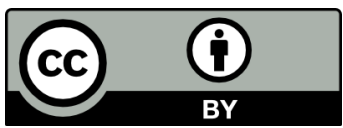

This publication is covered by a Creative Commons Attribution 4.0 International license. For further information please see: http://creativecommons.org/licenses/by/4.0/. 